Article

\title{
VisualUVAM: A Decision Support System Addressing the Curse of Dimensionality for the Multi-Scale Assessment of Urban Vulnerability in Spain
}

\author{
Jorge Salas ${ }^{1(D)}$ and Víctor Yepes ${ }^{2, *(1)}$ \\ 1 School of Civil Engineering, Universitat Politècnica de València, 46022 Valencia, Spain; \\ jorsaher@doctor.upv.es \\ 2 ICITECH, Universitat Politècnica de València, 46022 Valencia, Spain \\ * Correspondence: vyepesp@cst.upv.es; Tel.: +34-963-879-563; Fax: +34-963-877-569
}

Received: 12 March 2019; Accepted: 11 April 2019; Published: 12 April 2019

check for updates

\begin{abstract}
Many-objective optimization methods have proven successful in the integration of research attributes demanded for urban vulnerability assessment models. However, these techniques suffer from the curse of the dimensionality problem, producing an excessive burden in the decision-making process by compelling decision-makers to select alternatives among a large number of candidates. In other fields, this problem has been alleviated through cluster analysis, but there is still a lack in the application of such methods for urban vulnerability assessment purposes. This work addresses this gap by a novel combination of visual analytics and cluster analysis, enabling the decision-maker to select the set of indicators best representing urban vulnerability accordingly to three criteria: expert's preferences, goodness of fit, and robustness. Based on an assessment framework previously developed, VisualUVAM affords an evaluation of urban vulnerability in Spain at regional, provincial, and municipal scales, whose results demonstrate the effect of the governmental structure of a territory over the vulnerability of the assessed entities.
\end{abstract}

Keywords: multi-scale assessment; visual analytics; cluster analysis; curse of dimensionality; urban vulnerability assessment; many-objective

\section{Introduction}

Urban vulnerability (UV) in general, and its adaptive component in particular, have become key issues for a sustainable urban development [1-4] which have lead, in recent decades, to the improvement of the existing urban vulnerability assessment models (UVAMs). In the pursuit of this, several requirements have been pointed out, all of which should be simultaneously addressed by vulnerability assessment methods in order to integrate vulnerability assessment into current urban strategic planning (USP) [2,5] and fill the gap between assessment and actions [6]. Specifically, the advancement in multi-scale assessment methods is needed to afford a multi-scale assessment framework providing an integrated evaluation of entities at the three relevant levels of government (Central government, regions, and cities), with which to avoid resources allocation problems [7,8].

Dor and Kissinger [9], as well, pointed out the importance and need of analysing the potential contribution of measures to urban sustainability at the top and down scales of a system, while Rega et al. [10] remarked the relevance of the political-administrative context (region, province, cities) when assessing a territory's urban sustainability. This work contributes the need of having into account the governmental structure when developing comprehensive assessment models by demonstrating the influence of entities' governmental context risk-level over entities' risk of increasing vulnerability (e.g., the influence of a region's risk over its provinces' risk and so on). Following this idea, the presented 
methodology provides the holistic and multi-scale quantitative assessment required for achieving urban sustainability [9] and demanded by Strategic Environmental Assessment [10]. While other methodologies have undertaken the evaluation of resilience at buildings, parcels, neighbourhoods and communities scales [4], this study investigates the effect of entities' political-administrative context's risk over entities' risk at the municipal, provincial and regional scales of urban vulnerability. This multi-scale assessment meets the requirements for being integrated into strategic planning to produce a comprehensive plan of actions, to be implemented at local (down) scale, contributing to ameliorate vulnerability at national (top) scales [8].

This paper presents a Decision Support System (DSS) implementing a methodology previously developed [11] to provide an urban vulnerability assessment of Spain at regional, provincial, and city scales that can be integrated into strategic planning tools for ameliorating this problem [8]. The DSS is a Multi Objective Optimization (MOO) decision-making tool [12] for simultaneously addressing all the requirements pointed out for vulnerability assessment, as well as for searching the set of indicators best representing urban vulnerability accordingly to several objectives. These objectives were closeness to expert judgment, maximise goodness of fit of the statistical model representing vulnerability's evolution over time, and the robustness of each set of indicators against data uncertainty [11]. As a result, the method rendered several sets of indicators among which the decision-makers had to choose.

This selection, on the other hand, may be hindered by a dimensional problem with the number of available alternatives rendered by the process.

Zio and Bazzo [13] pointed out that only a manageable number of alternatives, representing the Paretofront, should be offered for selection to the DMs. However, MOO processes typically yield a large amount of solutions [14], seeming a cloud of solutions rather than a manageable set of them. This particularity more patently affects many-objective configurations [15], especially in the presence of conflicting or not aligned objectives, as in the case of selectin urban UVAMs. The large amount of solutions, also called the "curse of dimensionality" by Kukkonen and Lampinen [16] (Figure 1, Step 1), requires a specific treatment enabling DMs to focus their attention on those alternatives found relevant [11]. The employment of data analytics, such as cluster analysis [13,17,18], or visual analytics, such as "brushing" solutions $[19,20]$, have previously been used for alleviating the problem of unmanageable sets of alternatives. However, there is a lack of such approaches to reduce the dimension of solutions provided by UVAM selection decision frameworks.

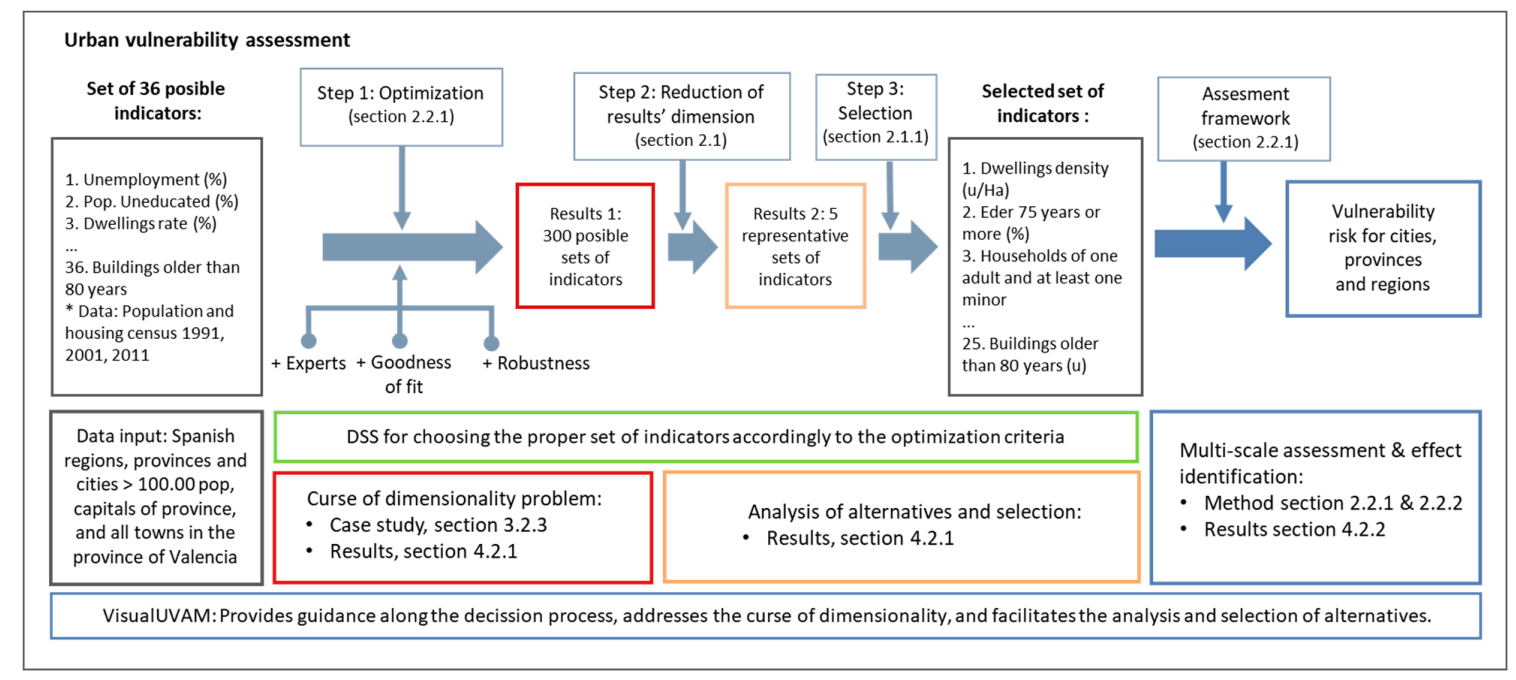

Figure 1. Flowchart of the process.

The presented decision support system addresses this problem by extensive usage of visual analytics all along the decision process with the aim of selecting a proper UVAM (Figure 1, Step 3) for the assessment of UV in Spanish regions, provinces, and cities larger than 100,000 people, capitals of 
provinces, and all municipalities in the province of Valencia. On one hand, visual analytics (Figure 1) allow focusing the analysis into a limited decision space, interactively bounded by the analyst. On the other hand, the decisional tool presented enables DMs to synthesise, by means of cluster analysis (Figure 1, Step 2), the space of solutions into a manageable number of representative ones, facilitating the process of analysing alternatives and selecting the proper one. Visual analytics allow for an ex post, dynamic selection of the criteria employed to choose the representative solutions of each cluster, as well as the number of clusters desired by the analyst, improving the extraction of knowledge. The whole DSS is implemented as a software, which we have denominated VisualUVAM, in order to provide the decision-makers with the necessary guidance along the whole process, allow the necessary interactions between the decision-makers and the process, and enable them to interactively set up both the bounds required to limit the space of solutions, as well as the necessary parameters for synthesizing them.

Thus, the novelty of the presented DSS relies, on one hand, in the innovative combination of clustering methods and visual analytics to solve the "curse of dimensionality" problem in the selection of UVAM, contributing to alleviating burdens on the decision-making task. On the other hand, the presented method affords for the first time a comprehensive and multi-scale assessment, from national to municipal scales, of urban vulnerability throughout a territory. Based on the results yielded by this methodology, this work has been the first in identifying, on a quantitative footing, the effect of the context's risk of vulnerability over an entity's risk, which underpins the idea of vulnerability's propagation across scales pointed out by Adger [21].

The remainder of this paper is organised as follows. In the methods section, both the decision-making framework and the assessment model are presented, along with a description of the information collection process. Then, two tools, designed accordingly to this methodology, are presented in the following section. The first one gathers and transforms the qualitative information required by the second, which articulates the decisional model for selecting UVAMs. Along with this section, the implementation of these tools on Spain, as well as the results produced by their operation, are portrayed to the reader. Finally, conclusions are drawn in the final section.

\section{Methods}

\subsection{Decision-Making Framework: Addressing the Curse of Dimensionality}

Frequently, solving real life decision problems involves decision-making, affecting different objectives whose interests are often not aligned and may even be opposed. This type of situation is an ideal context in which to apply MOO techniques, in order to locate the compromise solutions representing points of equilibrium. Compromise solutions are those satisfying several objectives simultaneously, such that there are no other solutions improving any of these objectives without worsening some of the others. In prior work, Salas and Yepes [11] employed the multi-objective approach to find out sets of indicators better representing urban vulnerability accordingly to some characteristics. These characteristics were closeness to expert judgment, goodness of fit of the statistical model representing vulnerability's evolution along time, and the robustness of each set of indicators against data uncertainty (Figure 1, Optimization). This methodology, however, afforded a large number of possible solutions, still unmanageable for the decision-makers, which are synthesised into a smaller number of representative ones by means of visual analytics and cluster analysis (Figure 1, reduction of results' dimension).

\subsubsection{Visual Analytics}

In effect, the outcomes produced by each step of the method are sets of alternatives, evaluated in the light of different criteria, which are represented by a large amount of information [22]. To address this, interactive visual analytics use different data visualisation techniques, offering multiple, linked views of relevant information $[23,24]$. Therefore, the decision tool displayed graphics and tables simultaneously, portraying relevant information to understand the trade-offs between selection criteria [25]. 
In addition, the decision-maker was enabled, through sliders controls, to dynamically "tune" the meeting criteria for "brushing" solutions [20]. By means of this feature, the DM is enabled to focus the analysis on those alternatives meeting the required criteria, which can interactively be set up during the process by specifying threshold values for the objectives employed in the MOO process (Figure 2).

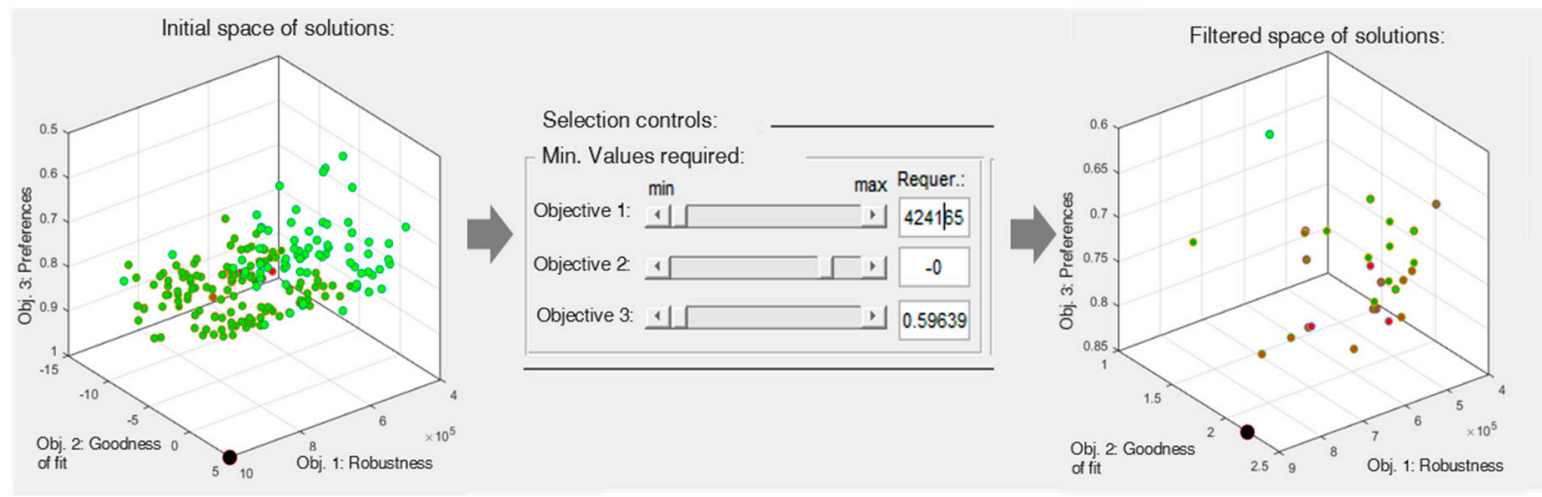

Figure 2. Delimitation of the space of solutions through visual analytics and selection controls.

\subsubsection{Cluster Analysis}

Along with the filtering of solutions, the process allows us to synthesise them into k partitions, following Lloyd's algorithm, also known as the k-mean clustering method [13,18]. Cluster analysis is a multivariate analysis technique that aims to organize information about variables so that relatively homogeneous clusters can be formed. The k-means clustering method is known for its efficiency in clustering data sets. This grouping is done by evaluating each cluster's centroid, and then attaching observations to the closest centroid's group [18]. In our approach, the observations are the solutions rendered by the MOO, while the data are the results yielded by the observations for each objective. Therefore, each cluster consists of solutions with similar behaviour from the results point of view, which are the relevant criteria for the decision-maker.

Once the set of alternatives is generated, the presented method enables the decision-maker to interactively select both the number of " $k$ " partitions in which the alternatives will be divided, as well as the criterion to be employed for selecting the representative solutions. Accordingly, the set of alternatives is first divided into " $\mathrm{k}$ " sub-sets of alternatives. Each sub-set of solutions $C \mathrm{j}=1, \ldots, \mathrm{K}$, obtained by the k-means clustering algorithm contains a number $n \mathrm{j}$ of solutions of similar characteristics in the objective functions space and whose best representative solution, needs to be found accounting for the DM specific requirements. Thanks to the implementation of the proposed methodology as a software, the decision-makers are enabled to interactively choose which criterion, among those driving the search in the MOO process, will be employed for determining the best representative solution, i.e., that performing best for the selected objective. This way, the decision tool makes it possible to go from an unmanageable number of compromise solutions to an affordable number of relevant alternatives that can be handled by the decision-making team.

\subsection{Multi-Scale Urban Vulnerability Assessment}

\subsubsection{Urban Vulnerability Assessment Framework}

Vulnerability can be defined, in broad terms, as the easiness that an entity presents to suffer from the negative effects of an event, or its difficulty in overcoming them.

The concept of UV embodied in the process mainly corresponds with that considered by the Spanish Ministry of Development in its Observatory of Urban Vulnerability (OUV) [26]. According to this, an entity is vulnerable when its value, for any of the basic indicators, goes beyond the reference value, calculated as 1.5 (vulnerability threshold) times the national average (base of vulnerability). The basic 
indicators considered by the Ministry [26] to discriminate between vulnerable and non-vulnerable entities are:

- Unemployment rate. Percentage of unemployed individuals by all individuals currently in the labour force.

- Education index: Percentage of illiterate population and without education.

- Housing index: Percentage of population living in dwellings without bathroom or water closet within the dwelling.

Based on this first basic characterisation, classifying the entities as vulnerable or non-vulnerable, the proposed assessment framework deepens in the analysis, establishing, using principal component analysis, an assessment of the state of vulnerability (SV) at a given time [11]. The higher the relationship, the more vulnerable the entity considered will be. As a result, an evaluation of each entity's SV is obtained, positioning them in the vulnerability ranking.

The evolution of the vulnerability state, on the other hand, is considered as its variation along a given period. In our case, this evolution was studied, for periods 1 (1991-2001) and 2 (2001-2011), as the difference between the states of vulnerability at the end and at the beginning of each of these periods. Based on this evolution we obtained, through discriminant analysis, the probability of each entity to continue increasing, reducing, or maintaining its level of vulnerability and, by means of linear regression, the impact with which it would change [11]. These two concepts, probability and impact, combine to determine the risk of each entity to increase its vulnerability.

These entities, on the other hand, are arranged into governmental structures such as cities, provinces, regions, and countries. In order to enable a comprehensive analysis of the urban vulnerability problem, the assessment methodology accounts for this political-administrative structure by selecting the most suitable set of indicators for each scale and provides an assessment of entities across all levels. This approach was operated in the MOO process by generating independent sets of decision variables by scale, each of which containing all possible indicators, and by including independent objectives of goodness of fit by scale, so that the MOO algorithm sought for the most suitable set of indicators by scale [11]. Then, these sets of indicators were used to build independent assessment models by scales, which enabled the evaluation of entities at city, province, and region scales.

For further details of the assessment framework model and its theoretical foundations, the reader is encouraged to consult prior studies $[5,11,21,27]$.

\subsubsection{Identification of the Multi-Scale Effect of Urban Vulnerability}

The results from the above framework allow for analysing entities not only as a function of their own characteristics, but also to contextualize them regarding their governmental context, which would be of help in understanding to which extent entities would be affected by their political-administrative environment, i.e., how urban vulnerability propagates between scales. In order to investigate whether there exists or not such influence, we developed a methodology by which we established three levels of vulnerability risk for each entity, and analysed the connection of entities' risk with the following variables among scales:

- $\quad$ SVij is the state of vulnerability of the $j$ entity at $i$ scale with $j \in(1, \ldots, n)$, and $i \in(1, \ldots, m)$, where $n$ is the number of entities at $i$ scale, and $m$ is the number of scales in the territory assessed.

- SVEij is the state of vulnerability's evolution of the $j$ entity at i scale

- CRLij represents the context's risk level of the j entity at i scale, which would be low (CRL-Low), medium (CRL-Medium), or high (CRL-High) depending on whether the corresponding entity at the upper scale's position was in the first, second, or last third of the risk rank at the upper scale.

We therefore computed each entity's CRL as the risk level of its corresponding entity at the upper scale, which enabled us to build a regression model with two quantitative predictors (SV and SVE), one categorical predictor (CRL), and one response (entities' risk). In a regression model, $p$-values lower 
than 0.05 indicate a significant influence of this variable over the entity's risk, while high coefficients in a variable indicates a high impact on the response [28].

Finally, we resorted to the analysis of variance for specifically analyse the influence of the context (CRL variable) over the entities' risk. By means of the Welch's test (Non-parametric ANOVA), we sought to identify the effect of the contexts risk levels (low, medium, and high) over the entities' risk. We performed a one-way Welch's test with the three levels of the CRL variable as input variable, and entities' risk as response. As in the case of the regression model, $p$-values lower than 0.05 would indicate a significant effect of this level over the response.

\section{Case Study: Assessing Urban Vulnerability in Spain}

\subsection{Information Collection Process}

\subsubsection{Quantitative Information}

The compilation of the quantitative information relative to all the municipalities of the province was downloaded from the web of the National Institute of Statistics, with the necessary data of each municipality obtained. This information was added to that already collected, regarding cities in Spain with more than 100,000 inhabitants or provincial capitals. In summary, the information gathered involved 36 indicators (Table 1) for each of the 403 cities (264 of which are from the province of Valencia), 52 provinces (including Ceuta and Melilla), and 19 regions (including the autonomous cities of Ceuta and Melilla as regions) that composed the elaborated database. This information was collected for years 1991, 2001, and 2011, allowing to analyse the evolution of urban vulnerability in the periods 1991-2001 and 2001-2011.

Table 1. Relative Preferences of Experts and comparison with Preferences of the Urban Vulnerability Observatory (OUV).

\begin{tabular}{|c|c|c|c|c|c|c|c|c|}
\hline \multirow[b]{2}{*}{ Approach } & \multirow[b]{2}{*}{$\operatorname{Imp}$} & \multirow[b]{2}{*}{ Aspects } & \multirow[b]{2}{*}{$\operatorname{Imp}$} & \multicolumn{2}{|r|}{ Indicators } & \multirow[b]{2}{*}{ Importance } & \multirow[b]{2}{*}{ Rank } & \multirow[b]{2}{*}{$\begin{array}{c}\text { OUV's } \\
\text { Importance }\end{array}$} \\
\hline & & & & ID & Description & & & \\
\hline \multirow{13}{*}{$\begin{array}{l}\text { Socio- } \\
\text { Economic } \\
(\mathrm{SE}) \\
\text { Aspects }\end{array}$} & \multirow{13}{*}{51.81} & \multirow{5}{*}{$\begin{array}{l}\text { Social } \\
\text { Structure } \\
\quad(\mathrm{SS})\end{array}$} & \multirow{5}{*}{27.68} & 1 & Area Population & 3.64 & 11 & 0 \\
\hline & & & & 2 & Population density (pop/ha) & 8.84 & 1 & 0 \\
\hline & & & & 3 & Eder 75 years or more (\%) & 5.85 & 3 & 0 \\
\hline & & & & 4 & $\begin{array}{l}\text { Households of one person older than } \\
64 \text { years }(\%)\end{array}$ & 3.68 & 10 & 0 \\
\hline & & & & 5 & $\begin{array}{l}\text { Households of one adult and at least } \\
\text { one minor }(\%)\end{array}$ & 5.67 & 4 & 0 \\
\hline & & \multirow{4}{*}{$\begin{array}{l}\text { Economic } \\
\text { Strucure } \\
\text { (ES) }\end{array}$} & \multirow{4}{*}{11.49} & 6 & Unemployment rate (\%) & 4.47 & 5 & 33 \\
\hline & & & & 7 & Youth unemployment rate (\%) & 1.99 & 21 & 0 \\
\hline & & & & 8 & Temporary employee (\%) & 2.02 & 20 & 0 \\
\hline & & & & 9 & Unqualified workers (\%) & 3 & 14 & 0 \\
\hline & & \multirow{4}{*}{$\begin{array}{l}\text { Educational } \\
\text { level (EL) }\end{array}$} & \multirow{4}{*}{12.64} & 10 & Population uneducated (\%) & 4.24 & 6 & 33 \\
\hline & & & & 11 & Population with primary education (\%) & 3.8 & 8 & 0 \\
\hline & & & & 12 & $\begin{array}{l}\text { Population with secondary } \\
\text { education }(\%)\end{array}$ & 1.75 & 24 & 0 \\
\hline & & & & 13 & Population with higher education (\%) & 2.85 & 15 & 0 \\
\hline
\end{tabular}


Table 1. Cont.

\begin{tabular}{|c|c|c|c|c|c|c|c|c|}
\hline \multirow[b]{2}{*}{ Approach } & \multirow[b]{2}{*}{$\operatorname{Imp}$} & \multirow[b]{2}{*}{ Aspects } & \multirow[b]{2}{*}{$\operatorname{Imp}$} & \multicolumn{2}{|r|}{ Indicators } & \multirow[b]{2}{*}{ Importance } & \multirow[b]{2}{*}{ Rank } & \multirow[b]{2}{*}{$\begin{array}{c}\text { OUV's } \\
\text { Importance }\end{array}$} \\
\hline & & & & ID & Description & & & \\
\hline \multirow{23}{*}{$\begin{array}{c}\text { Bio- } \\
\text { Physical } \\
\text { (BF) } \\
\text { Aspects }\end{array}$} & \multirow{23}{*}{48.19} & \multirow{3}{*}{$\begin{array}{c}\text { Area } \\
\text { Occupation } \\
(\mathrm{AO})\end{array}$} & \multirow{3}{*}{9.6} & 14 & Number of dwellings $(\mathrm{u})$ & 1.65 & 25 & 0 \\
\hline & & & & 15 & Dwellings density $(\mathrm{u} / \mathrm{Ha})$ & 6.15 & 2 & 0 \\
\hline & & & & 16 & Area (Ha) & 1.8 & 22 & 0 \\
\hline & & \multirow{6}{*}{$\begin{array}{l}\text { Dwellings } \\
\text { Condition } \\
\text { (DC) }\end{array}$} & \multirow{6}{*}{11.75} & 17 & $\begin{array}{l}\text { Dwellings rate (\% Population with no } \\
\text { WC in the dwelling) }\end{array}$ & 1.05 & 31 & 33 \\
\hline & & & & 18 & Dwellings in ruin condition (\%) & 3.4 & 13 & 0 \\
\hline & & & & 19 & Dwellings in bad condition (\%) & 2.6 & 17 & 0 \\
\hline & & & & 20 & Dwellings in deficient condition (\%) & 1.77 & 23 & 0 \\
\hline & & & & 21 & Dwellings in good condition (\%) & 1.29 & 30 & 0 \\
\hline & & & & 22 & Dwellings without running water (\%) & 1.64 & 26 & 0 \\
\hline & & \multirow{5}{*}{$\begin{array}{l}\text { Dwellings } \\
\text { Size (DS) }\end{array}$} & \multirow{5}{*}{16.37} & 23 & Dwellings with less than $30 \mathrm{~m}^{2}(\%)$ & 2.75 & 16 & 0 \\
\hline & & & & 24 & Dwellings total usable surface $\left(\mathrm{m}^{2}\right)$ & 2.5 & 18 & 0 \\
\hline & & & & 25 & Mean usable surface by dwelling $\left(\mathrm{m}^{2}\right)$ & 3.88 & 7 & 0 \\
\hline & & & & 26 & Mean usable surface by habitant $\left(\mathrm{m}^{2}\right)$ & 3.44 & 12 & 0 \\
\hline & & & & 27 & $\begin{array}{l}\text { Number of rooms by dwelling } \\
(\mathrm{u} / \mathrm{dwell})\end{array}$ & 3.8 & 9 & 0 \\
\hline & & \multirow{4}{*}{$\begin{array}{l}\text { Dwellings } \\
\text { Usage } \\
\text { (DU) }\end{array}$} & \multirow{4}{*}{5.63} & 28 & Main Dwellings (u) & 1.05 & 32 & 0 \\
\hline & & & & 29 & Empty Dwellings (u) & 2.34 & 19 & 0 \\
\hline & & & & 30 & Owned Dwellings (u) & 0.76 & 34 & 0 \\
\hline & & & & 31 & Rented Dwellings (u) & 1.48 & 28 & 0 \\
\hline & & \multirow{5}{*}{$\begin{array}{l}\text { Dwellings } \\
\text { age (DA) }\end{array}$} & \multirow{5}{*}{4.84} & 32 & $\begin{array}{l}\text { Dwellings in builds built before } \\
\qquad 1951(\%)\end{array}$ & 1.49 & 27 & 0 \\
\hline & & & & 33 & Total buildings $(\mathrm{u})$ & 0.44 & 36 & 0 \\
\hline & & & & 34 & Buildings older than 30 years $(\mathrm{u})$ & 0.51 & 35 & 0 \\
\hline & & & & 35 & Buildings older than 50 years $(\mathrm{u})$ & 1.45 & 29 & 0 \\
\hline & & & & 36 & Buildings older than 80 years $(\mathrm{u})$ & 0.96 & 33 & 0 \\
\hline
\end{tabular}

\subsubsection{Qualitative Information}

The analytic hierarchy process (AHP) is a multi-criteria technique usually employed to collect relative preferences between criteria based on verbal judgments $[29,30]$ which has already been employed for the gathering of preferences for indicators to be employed in assessing socio-economic aspects [31]. In the AHP, the preferences between the criteria within a group are determined by the principal right eigenvector method [32]. As for the hierarchical structure, independence between elements of different groups was assumed. In addition, the hierarchical composition principle was followed, multiplying successively the relative preferences of the dependent elements by the weight of the element on which they depend, to obtain the total priorities.

The AHP allows for the transformation of experts' verbal judgment into mathematical language, by pairwise comparisons on a set of criteria. However, the number of criteria being compared should not exceed five, since from this point, it becomes very difficult for a person to relate the set of concepts to each other [31]. Given that our case entails the comparison of 36 different criteria, they were structured in three levels, so that only in one case is the number of criteria to be compared greater than five. Basically, the structure adopted was a transposition of the conceptual framework adopted by the Spanish OUV, to which some indicators were added.

The AHP processes are, in many occasions, articulated in two steps, in which expert judgments are first collected through survey and then processed, only to discover, on many occasions, that judgments had an unacceptable consistency index. This leads to the repetition of the survey if possible, or to review the judgments maintaining priority in the trials [33]. Both alternatives entail time consumption and quality reduction. To avoid this problem, an application was developed in 
the form of computer software that informed the participants, as they made their judgments, about whether these were consistent or not, allowing experts to revise their judgements until they became acceptable. This software, programmed in Matlab and based on the AHP multi-criteria decision technique, instantly evaluates the consistency of the judgments, allowing their review at the moment and guaranteeing that the evaluation issued by the expert meets the necessary technical requirements and is suitable for its aggregation to the process.

\subsection{Running of the Process}

The methodology designed for first selecting the set of indicators better representing urban vulnerability, and then for assessing it [11] was implemented in Visual UVAM, a software providing guidance across the selection process and affording the visualization of the assessment results. This software was programmed in Matlab ${ }^{\circledR}$, while the graphic interface was designed with Matlab's Gui extension. The guidance of the process is achieved by structuring it in a series of steps, which must be completed sequentially with the help of the control and visual analytics provided in the software (Figure 3).

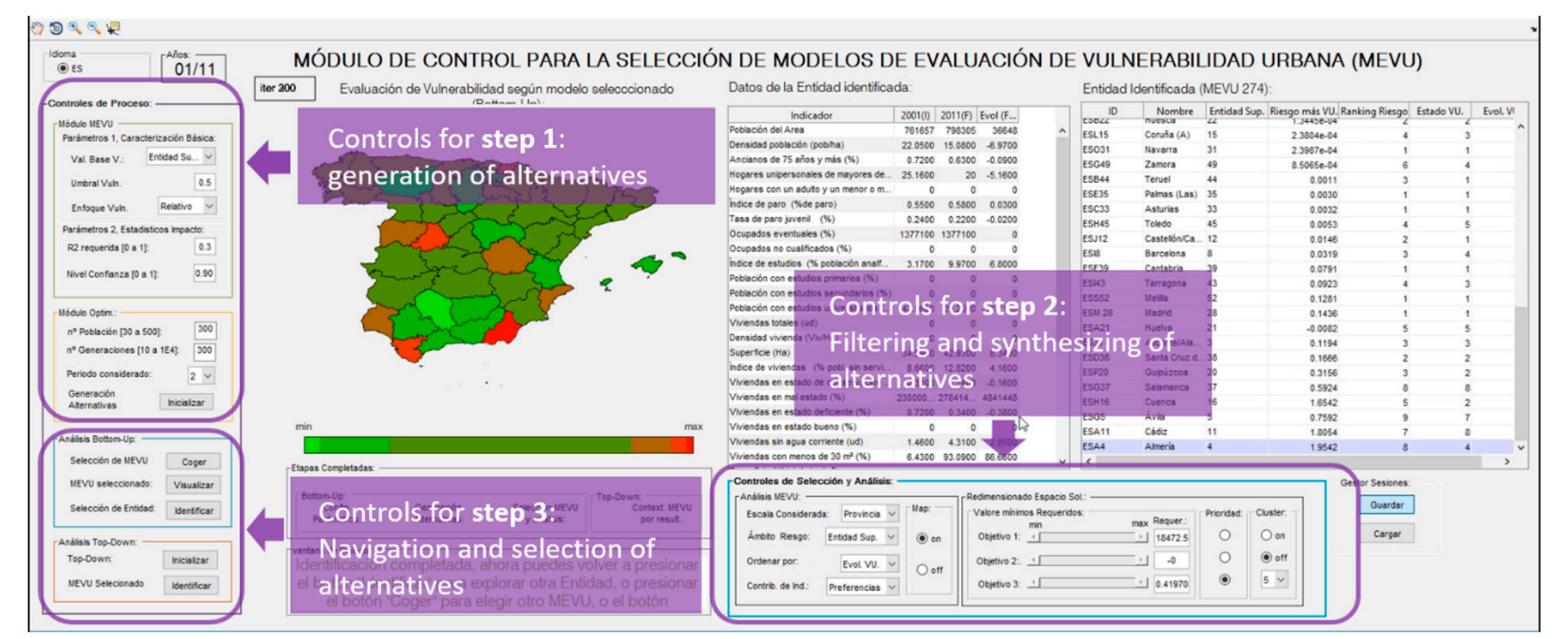

Figure 3. Completion of the decision process with the aid of VisualUVAM. UVAM, urban vulnerability assessment model.

- Step 1, optimization (Figures 1 and 3, Step 1):

In this stage, the desired values are introduced for the basic characterisation parameters, described in Section 2.2, UV assessment framework:

- Value taken as a base of vulnerability

- Vulnerability threshold

- Vulnerability Approach

The statistical requirements that the regression with which the impact value is determined, used to calculate the risk of each entity, can also be configured.

Once the values for the basic characterization are introduced, VisualUVAM generates optimal sets of indicators accordingly to the objectives specified in Section 2.2. The search is controlled with two parameters, which define the number of alternatives to be handled, and the number of iterations that must be followed in the search process. The greater the number of alternatives and iterations, the better the quality of the search will be, but it will require more computing time. From 300 alternatives and 200 iterations, models with an acceptable quality are obtained. As a result of this generation, a set of 300 alternatives, each one being a set of indicators for assessing urban vulnerability, was obtained. 
- Step 2, addressing the curse of dimensionality (Figures 1 and 3, Step 2):

Once the set of alternatives has been generated, it can be resized by specifying the required values for each objective or synthesised by cluster analysis. In the first case, only those solutions simultaneously meeting the values required will be presented to the decision-maker for its further analysis (Section 2.1.1), while in the second case, the alternatives will be synthesised in a pre-defined number of relevant alternatives by means of cluster analysis (Section 2.1.2).

- Step 3, selection of alternatives (Figures 1 and 3, Step 3):

Once the dimension of the initial set of solutions has been reduced to a point enabling the decision-maker to perform its duty, this latter can choose the proper solution based on the criteria employed to generate alternatives. Since we analysed vulnerability along two time periods (1991-2001 and 2001-2011) and each one required its own assessment model [11], we made two choices. For the first period (1991-2001), we recurred to the cluster analysis to synthesize all the solutions available into nine representative ones. Considering that for a model to be acceptable it should that have a positive statistical adjustment and is at least $80 \%$ close to the preferences of the experts, and at the same time it should be the most robust among the synthesised solutions, we chose the model with ID 118. From the bottom-up point of view, comparatively with the rest of the representative solutions of each cluster, this solution would have a good behaviour in the subjective preference criteria (2nd), as well as being the second best in the robustness criterion.

For the last period (2001-2011), we resorted to visual analytics to reduce the space of solutions by imposing conditions to the alternatives. We analysed only those with positive statistical goodness of fit, among which we chose that with the best robustness and the second-best preferences among them (ID 274).

\section{Results and Discussion}

This section is divided into two parts: in the first part, the results of the consultation with experts are first presented and then discussed. In the second part, the results of the decision support system for addressing the curse of dimensionality and assessing urban vulnerability are also presented and discussed.

\subsection{Evaluation of Expert's Relative Preferences}

As indicated in Section 3.1.2, the AHP method was used to gather the preferences of the experts and consult about the indicators that, in their opinion, are of more help when it comes to characterising UV. With the help of Divalterra, a public company dependent of the Valencia Provincial Council, the survey was conducted among officials being expert in urban planning of municipalities in the province of Valencia, with a result of 11 responses gathered.

Figure 4 allows us to appreciate that preferences for the socio-economic (SE) or biophysical (BF) approaches are quite similar, suggesting the use of comprehensive approaches, which make use of both. Regarding the level of aspects, the two most representative are the social structure (SS) and the dwellings size (DS) (Table 1). These aspects are the most preferred for the sociological and BF approaches, respectively, in line with the equality in the distribution of importance between both points of view. It is significant, among the biophysical aspects, the lower importance bestowed to the dwellings age (DA) and dwellings usage (DU) aspects in comparison with the other. The SS is, in contrast, clearly preferred to the other aspects of the SE approach.

The aspects of both the BF and the sociological approaches have a great heterogeneity in the value of their preferences, although these differences are more marked in the sociological approach.

At the level of indicators, the results of the analysis allow us to state that the most relevant, for the experts consulted, are those related to density, whether it is population density (indicator no. 2, population density (population/ha), preference value $=8.84$ ) or the density of dwellings (indicator no. 15 , dwellings density $(\mathrm{Viv} / \mathrm{Ha})$, preference value $=6.15)$. In addition, each of these indicators are 
the most representative in their respective classes, namely, SS and area occupation. The next two indicators in importance are also part of the SS aspect. Thus, the third and fourth positions in the ranking by importance from highest to lowest, are occupied by indicators 3 , elders of 75 years or more $(\%)$, and 5, households of one adult and at least one minor (\%), with some values of relative importance of 5.85 and 5.67, respectively. As can be seen in Figure 5, there are up to 11 indicators above the upper limit of the confidence interval of the mean (HighCI), and 18 below, which gives an idea of the range of possible values that the indicators can adopt.

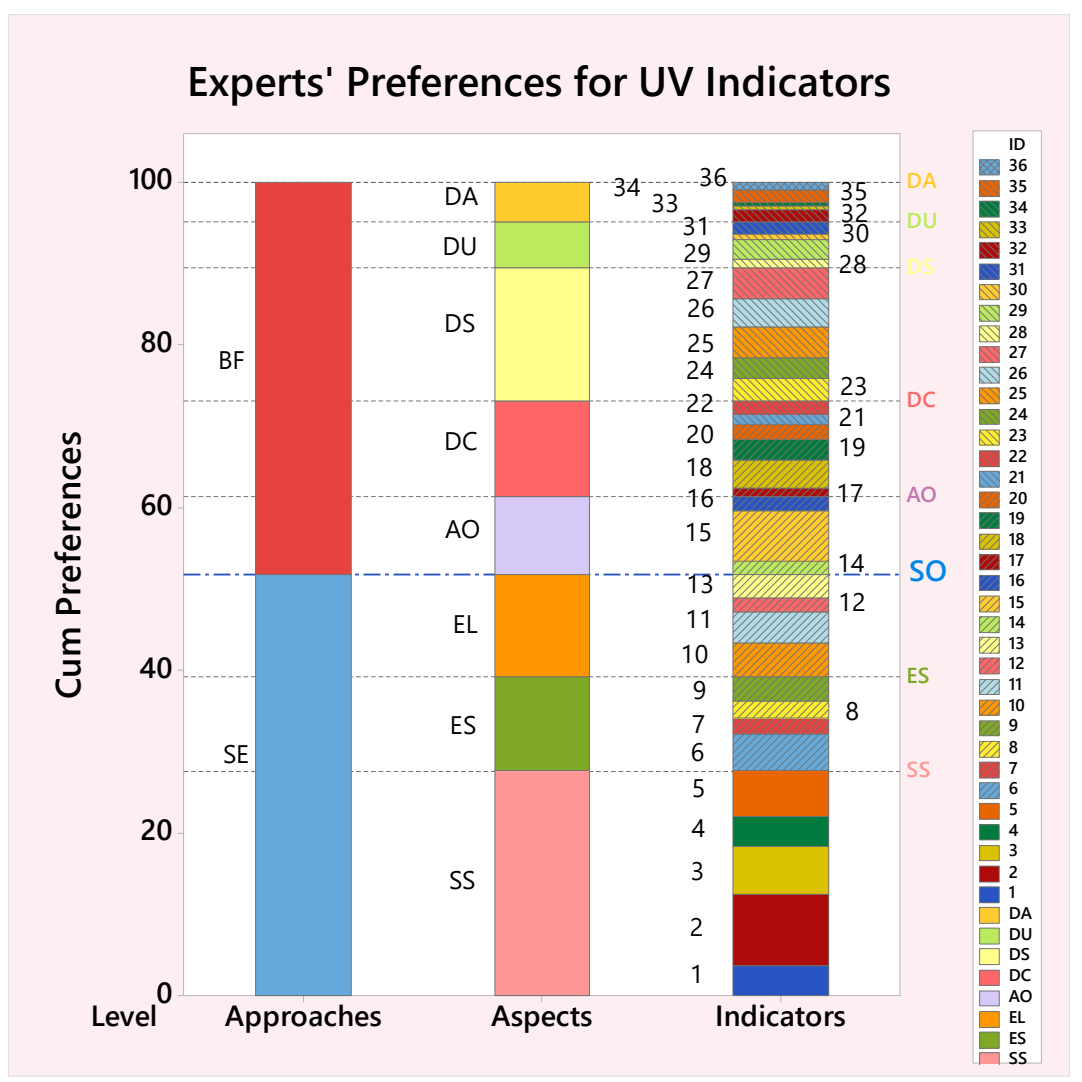

Figure 4. Relative preferences of experts for urban vulnerability assessment indicators. Indicators' ID correspond with Table 1 indicators.

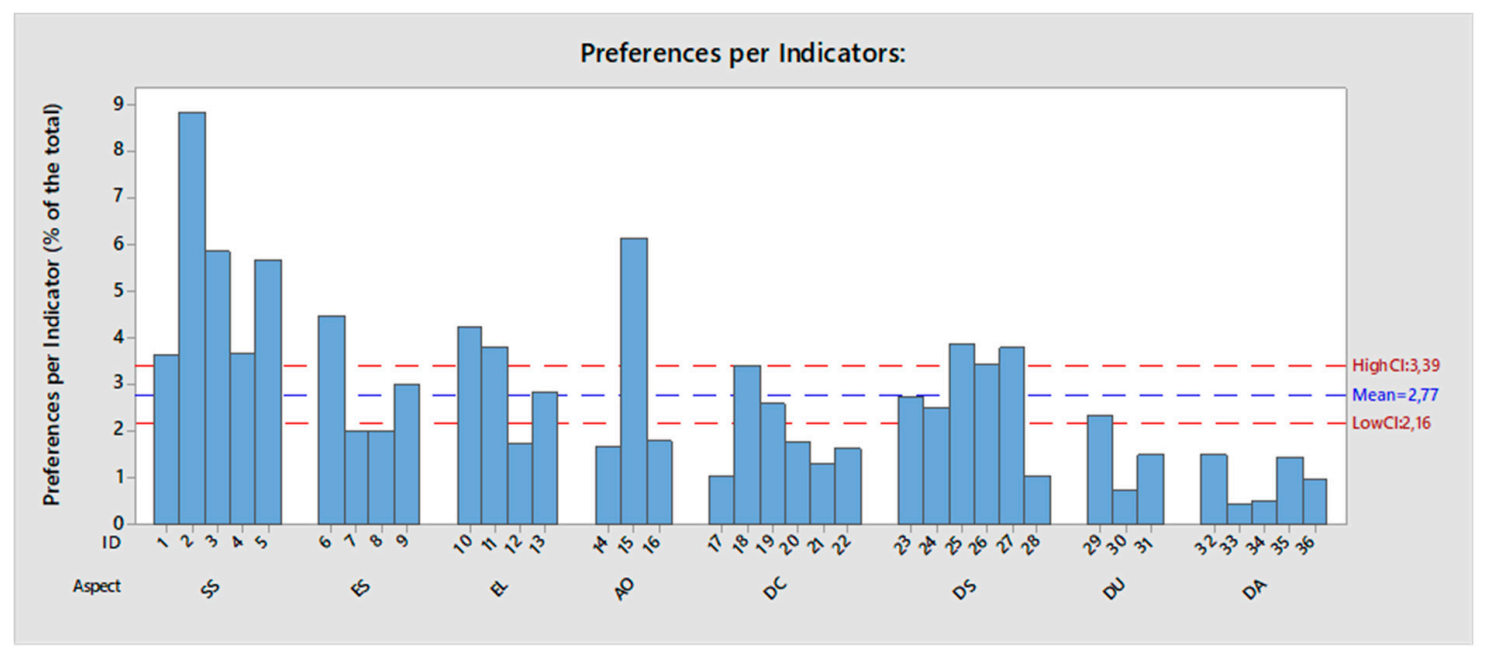

Figure 5. Preferences for indicators. Indicators' ID correspond with Table 1 . HighCI = upper limit confidence interval. LowCI $=$ lower limit of the confidence interval. 
Consistent with this idea, the values of both the first quartile $(\mathrm{Q} 1=1.4825)$ and the third quartile ( $\mathrm{Q} 3=3.77)$ fall outside the confidence interval. This indicates that the differences in relative importance between indicators cannot be disregarded or assimilated to an average value.

\subsection{Urban Vulnerability Assessment}

\subsubsection{Curse of Dimensionality}

Since the available data comprised information of two periods (1991-2001 and 2001-2011) and the process designed required the generation and selection of alternatives for each period, we carried out two choices.

In the first one, the initial set of 196 solutions was synthesised in a smaller set of five representative solutions by following the method based in cluster analysis (Section 2.1.2). In this case, we assigned priority to the "Goodness of fit" objective, which meant choosing the best in this objective among the solutions within each cluster as its representative. As a result, we obtained five representative solutions, among which we selected ID 118 since it offered the 2nd best performance in "Preferences" and "Robustness", and the 3rd in "Goodness of fit".

As to the second period, visual analytics (Section 2.1.1) enabled us to reduce the number of alternatives from 300 to 29 by selecting only those with a positive "Goodness of fit". Then, we resorted again to the cluster analysis method (Section 2.1.2) to synthesise the set of 29 solutions into a set of five representative solutions by assigning priority to the "Goodness of fit" criterion, which lead us to choose ID 274 as it performed the best in the "Robustness", and 2nd in the "Preferences" objective.

\subsubsection{Results of the Assessment and Identification of Multi-Scale Context's Effect}

The results of the analysis at the regional and municipal levels are attached in Supplementary Materials, while Table 2 shows the results at provincial scale.

Table 2. Results of the assessment at provincial scale.

\begin{tabular}{|c|c|c|c|c|c|}
\hline \multirow[t]{2}{*}{ ID } & \multirow[t]{2}{*}{ Province Name } & \multicolumn{4}{|c|}{ Ranking } \\
\hline & & Risk & State & State Evolution & Context's $(*)$ Risk Level \\
\hline 11 & Cádiz & 51 & 52 & 5 & 2 \\
\hline 14 & Córdoba & 3 & 42 & 4 & 0 \\
\hline 18 & Granada & 12 & 39 & 5 & 0 \\
\hline 21 & Huelva & 21 & 44 & 8 & 1 \\
\hline 23 & Jaén & 5 & 37 & 4 & 0 \\
\hline 29 & Málaga & 39 & 48 & -1 & 2 \\
\hline 4 & Almería & 52 & 43 & 14 & 2 \\
\hline 41 & Sevilla & 8 & 50 & 0 & 0 \\
\hline 22 & Huesca & 29 & 5 & 1 & 1 \\
\hline 44 & Teruel & 33 & 2 & 0 & 1 \\
\hline 50 & Zaragoza & 2 & 19 & -11 & 0 \\
\hline 33 & Asturias & 35 & 27 & -8 & 2 \\
\hline 38 & Santa Cruz de Tenerife & 46 & 47 & 4 & 2 \\
\hline 7 & Balears & 16 & 34 & -10 & 0 \\
\hline 35 & Palmas (Las) & 34 & 49 & 4 & 1 \\
\hline 39 & Cantabria & 41 & 21 & -7 & 2 \\
\hline 24 & León & 4 & 8 & -9 & 0 \\
\hline 34 & Palencia & 25 & 4 & -3 & 1 \\
\hline 37 & Salamanca & 48 & 15 & 1 & 2 \\
\hline 40 & Segovia & 24 & 3 & 0 & 1 \\
\hline 42 & Soria & 13 & 1 & 0 & 0 \\
\hline 47 & Valladolid & 10 & 17 & -8 & 0 \\
\hline 49 & Zamora & 32 & 6 & -3 & 1 \\
\hline 5 & Ávila & 49 & 11 & 1 & 2 \\
\hline
\end{tabular}


Table 2. Cont.

\begin{tabular}{|c|c|c|c|c|c|}
\hline \multirow[t]{2}{*}{ ID } & \multirow[t]{2}{*}{ Province Name } & \multicolumn{4}{|c|}{ Ranking } \\
\hline & & Risk & State & State Evolution & Context's $\left(^{*}\right)$ Risk Level \\
\hline 9 & Burgos & 40 & 7 & -6 & 2 \\
\hline 13 & Ciudad Real & 9 & 24 & 1 & 0 \\
\hline 16 & Cuenca & 50 & 16 & 10 & 2 \\
\hline 19 & Guadalajara & 1 & 12 & 4 & 0 \\
\hline 2 & Albacete & 15 & 23 & 3 & 0 \\
\hline 45 & Toledo & 36 & 28 & 4 & 2 \\
\hline 17 & Girona & 18 & 29 & -2 & 1 \\
\hline 25 & Lleida & 26 & 9 & -2 & 1 \\
\hline 43 & Tarragona & 42 & 32 & 0 & 2 \\
\hline 8 & Barcelona & 38 & 38 & -13 & 2 \\
\hline 12 & Castellón/Castelló & 37 & 26 & 0 & 2 \\
\hline 3 & Alicante/Alacant & 43 & 41 & -5 & 2 \\
\hline 46 & Valencia/València & 7 & 36 & -12 & 0 \\
\hline 10 & Cáceres & 27 & 30 & 8 & 1 \\
\hline 6 & Badajoz & 14 & 33 & -6 & 0 \\
\hline 15 & Coruña (A) & 30 & 31 & -6 & 1 \\
\hline 27 & Lugo & 23 & 14 & -2 & 1 \\
\hline 32 & Ourense & 17 & 22 & 3 & 0 \\
\hline 36 & Pontevedra & 28 & 35 & -5 & 1 \\
\hline 28 & Madrid & 45 & 40 & -12 & 2 \\
\hline 30 & Murcia & 22 & 45 & 3 & 1 \\
\hline 31 & Navarra & 31 & 13 & -14 & 1 \\
\hline 1 & Álava & 6 & 18 & -3 & 0 \\
\hline 20 & Guipúzcoa & 47 & 20 & 2 & 2 \\
\hline 48 & Vizcaya & 20 & 25 & -16 & 1 \\
\hline 26 & Rioja (La) & 11 & 10 & 5 & 0 \\
\hline 51 & Ceuta & 19 & 51 & 36 & 1 \\
\hline 52 & Melilla & 44 & 46 & 34 & 2 \\
\hline
\end{tabular}

$\left({ }^{*}\right)$ Context risk levels: $0=1$ st third; $1=2$ nd third; $2=3$ rd third.

The vulnerability maps at the provincial level of model 274 are represented in Figure 6, and they allow relatively analyse the state of vulnerability between entities at 2011, the evolution of the estate of vulnerability between 2001 and 2011, and the risk at 2011 of becoming more vulnerable. In broad, provinces with worst past evolutions present higher future risks.

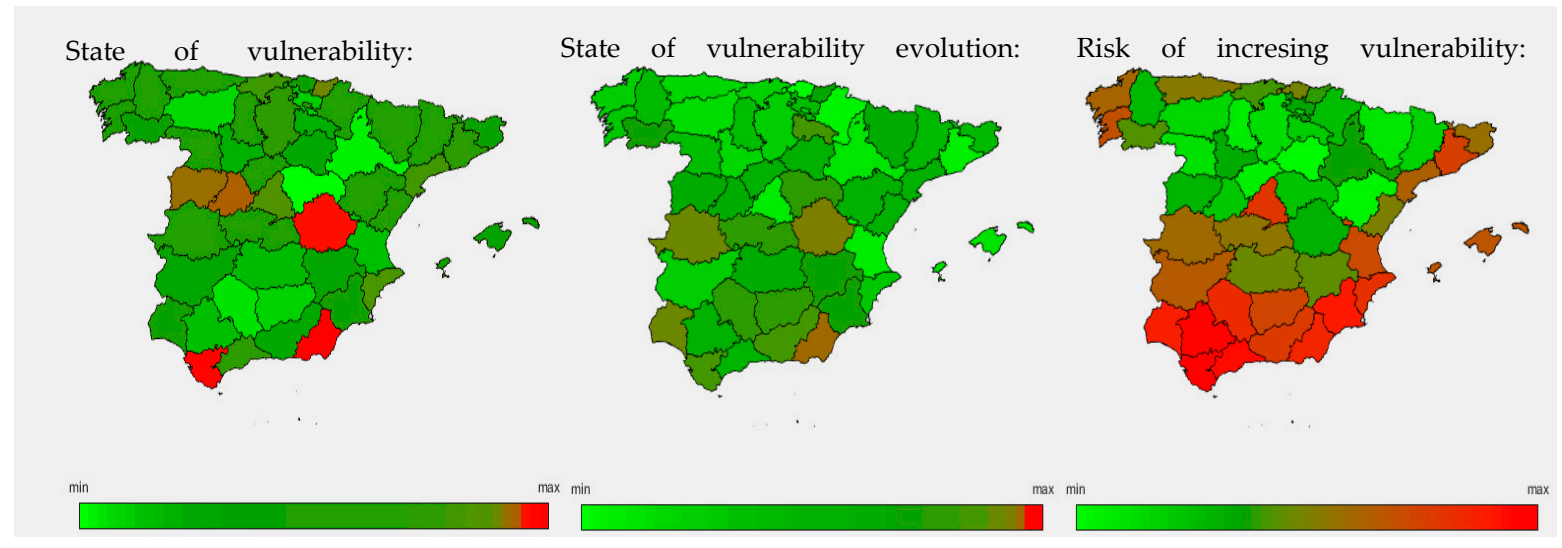

Figure 6. Maps of vulnerability at provincial scale.

Table 2 shows how there are provinces like Cuenca or Almeria whose state of vulnerability (SV rank $=16$ and 43) is lower than its risk and that, however, present a high risk of worsening 
(risk rank $=50$ and 52). This may be due to the significant increase in the state of vulnerability evolution (SVE) of these provinces (SVE $=10$ and 14), which lead us to check out the effect of this evolution upon the risk. We therefore built a regression model with two quantitative predictors (SV and SVE), and an additional categorical predictor, in order to determine whether the context's risk level (CRL) was influencing the entities' risk (Section 2.2.2). We modelled this context as the risk level of the upper entity to which any entity belongs (e.g., province of a city, region of a province and so on), and we assigned three levels or risk depending on whether an entity's position was in the first, second, or last third of the risk rank. The low p-values and high coefficient values of both the evolution of the state of vulnerability (SVE) and of the context's high-risk level (CRL-High) (Table 3), shows the significant influence of over entities' risk.

Table 3. Result of the regression model evaluating the assessment results.

\begin{tabular}{lcc}
\hline \multicolumn{2}{l}{ Regression Model R-sq(adj): } & $\mathbf{4 5 . 9 2 \%}$ \\
\hline Predictors: & Coefficient & $\boldsymbol{p}$-Value \\
\hline SV & -18.85 & 0.033 \\
SVE & 102.07 & 0 \\
CRL: & & \\
$\quad$ Low-Medium & 13.1 & 0.552 \\
High & 133.8 & 0 \\
\hline
\end{tabular}

Legend: SV—state of vulnerability; SVE—state of vulnerability's evolution; CRL —Context's risk level.

The above lead us to a further analysis, in which we resorted to the Welch's test (Non-parametric ANOVA) to check-out the effect CRL-High. With a p-value of 0 , the Welch's test also confirmed the effect of CRL-High level over entities' risk (Figure 7) (Section 2.2.2). This effect may help explain why provinces with a good evolution in the state of vulnerability such as Madrid and Barcelona have a relatively high risk (they belong to high-risk regions), while others like Valencia have a lower risk with the same evolution in its state of vulnerability (it belongs to a low-risk region).

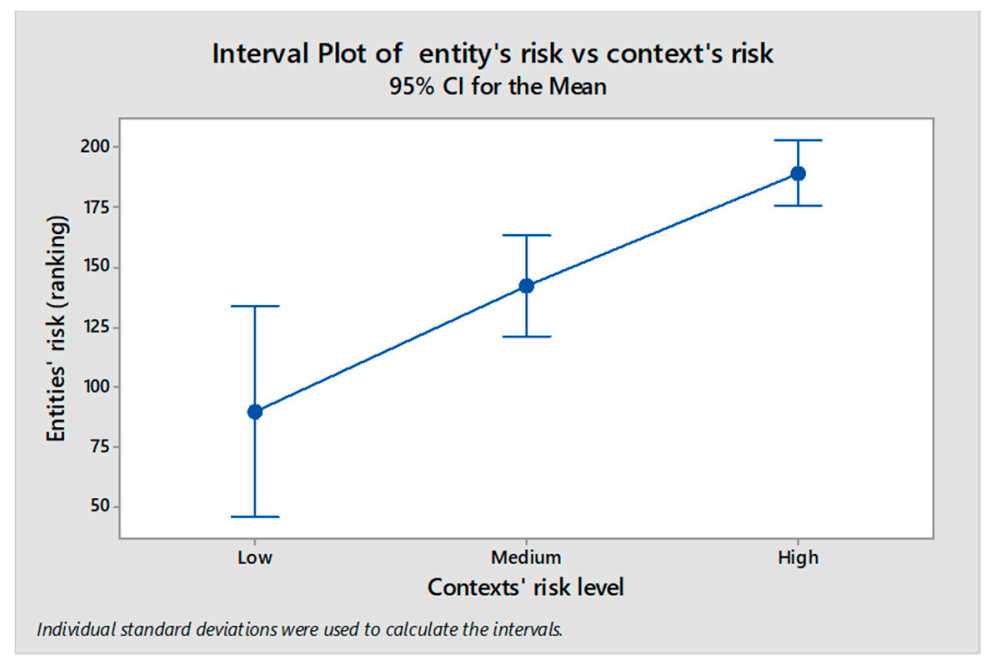

Figure 7. Results of the Welch's test analyzing the effect of the governmental contexts' risk level over entities' risk.

\section{Discussion}

\subsection{Results of Expert Judgment}

The identified heterogeneity in preferences assigned by experts to UV indicators (Figures 4 and 5) contrasts with the assumptions on which all the evaluation available in the OUV are based, which considers that all (unemployment, studies, and housing) indicators are equally important. 
On the other hand, none of the indicators considered in the analysis of the vulnerability observatory to estimate the intensity of vulnerability is found within the aspects considered most influential by the experts consulted (Table 1). Moreover, the three basic indicators employed by the OUV for assessing urban vulnerability sum up to $9,76 \%$ of the total preference, while the three indicators most preferred by experts sum up to $20,84 \%$, which depicts a sharp divergence between the OUV and the experts consulted.

All of the above suggest that it would be convenient to rethink the methodology used by the OUV by on the one hand considering a different set of basic criteria, and on the other by following an assessment methodology where the different importance of the indicators is taken into account.

\subsection{Results Yielded by the VisualUVAM Tool}

With regard to the curse of dimensionality problem, the employment of visual analytics and of cluster analysis enabled us to reduce the number of alternatives to a manageable number of them. We required that solutions must have a positive goodness of fit, and afterwards the resulting set of solutions was in turn synthesised into a set of five clusters. Then, by choosing the goodness of fit as criteria for selecting the representative solution of each cluster, we obtained five representative alternatives which we analysed until alternatives 184 and 274 were selected for periods 1 and 2, respectively. Overall, the decision support system enabled us to manage and reduce the initial set of 300 alternatives into a set of 5 alternatives, thus reducing the decisional burden for the decision-maker without loss of representative information.

On the other hand, the alternative selected afforded the quantitative assessment of the state and of the risk of urban vulnerability for entities of Spain at regional, national, and municipal scales, thus extending the multi-scale assessment previously developed at buildings, parcels, neighbourhoods, and communities scales [4]. This information enabled us to identify, by means of a regression model (Section 2.2.2), a significant relation between the state of vulnerability's evolution and the risk of increasing vulnerability (Table 3, SVE p-value $=0$ ). This model also indicated the significance of the high context risk level (Table 3, CRL-High p-value $=0$ ) over entities' risk, while the Welch's test also confirmed the effect of contexts' high-risk level (CRL-High) over the entities' risk (Figure 7). This propagation of vulnerability, from context to entities (higher to lower scales), reflects the multi-scale nature of vulnerability identified by Adger [21], and points out the need of considering such complex relations when assessing vulnerability.

The multi-scale assessment of urban vulnerability provided by VisualUVAM affords to evaluate how a set of mitigation alternatives, implemented at city scale, can contribute reducing vulnerability at different scales, and thus becomes a valuable information for addressing the problem of urban vulnerability by means of a comprehensive, and coordinated, urban strategic planning [8] addressing the gaps previously identified $[7,8]$.

\section{Conclusions and Further Research}

Throughout this research, a method for selecting urban vulnerability assessment models has been developed to obtain a tool that allows for the generation of results according to the latest trends in the field of urban strategic planning. The whole process was implemented in VisualUVAM, a software that integrates quantitative and qualitative information to find out relevant multi-scale assessment alternatives that satisfy the multiple criteria demanded for urban vulnerability assessment models. This process, however, yields a large number of pareto-optimal alternatives among which to decide, a problem for the decision-maker also known as the "curse of dimensionality". VisualUVAM addresses this problem by means of cluster analysis and visual analytics. Through an ex post selection of both the number of clusters and of the criterion used to choose the solution representative of each cluster, the proposed method synthesises the original set of alternatives into a manageable number of options, therefore alleviating the decisional burden entailed by a large set of alternatives. 
On the other hand, the proposed formulation of the urban vulnerability phenomenon considers its dynamic aspects over both time and the administrative structures in which it develops, offering a consistent and comprehensive assessment along the scales of municipality, province and region, and allows contextualising entities in terms of the risk of their correspondent entity at the upper scale (e.g., risk of the province to which a city belongs). Our work has demonstrated how high-risk level contexts contribute to increase the risk of vulnerability of the entities affected, underpinning the idea of vulnerability's propagation across scales, and pointing out the need of incorporating these relations by means of a multi-scale assessment of this phenomena. This approach also enables the design of comprehensive plans, implemented at city scale, for addressing urban vulnerability at national, regional, and provincial scales. Further, the results allow for analysing entities not only as a function of their own characteristics, but also to contextualize them with regard to their governmental context, which would be of help in understanding to which extent entities would be affected by their political-administrative environment.

In addition, this work presents a software that facilitates the collection of expert preferences, allowing them to check the consistency of their judgments in real time, review them before its submission, and therefore improve the quality of this analysis. For the experts consulted, the most relevant indicators in order of priority are the population density (inhabitants per hectare), the density of housing (Viv/Ha), the percentage of elderly people aged 75 and over $(\%)$, and the percentage of unipersonal households over 64 years of age (\%). At the level of aspects, the most important are the social structure and dwellings size. These results contrast strongly with the criterion used in the analysis of the Spanish Observatory of Urban Vulnerability, based on only three indicators, considering them equally important.

Despite the importance of the contributions indicated, the method developed during this research still contains limitations. The assessment framework employed is based on that of the Observatory of Urban Vulnerability, which proposes a basic classification of vulnerable or non-vulnerable entities based on the exceeding of a reference value in any of the basic indicators. However, the results of this research force us to question the suitability of the selected indicators. Therefore, it is necessary to deepen the study of the most appropriate set of basic indicators.

Supplementary Materials: The following are available online at http:/www.mdpi.com/2071-1050/11/8/2191/s1, Table S1: Assessment results.

Author Contributions: This paper represents a result of teamwork. J.S. and V.Y. jointly designed the research and developed the methodology. J.S. developed the software, carried out the investigation and drafted the original manuscript, and V.Y. revised and improved the manuscript.

Funding: This research was funded by the Spanish Ministry of Economy and Competitiveness, along with FEDER, grant number Project: BIA2017-85098-R".

Acknowledgments: The authors want to thank the staff of the department of strategic planning of Divalterra (Valencia Provincial Council) for their support in gathering qualitative information, testing and enhancing the decisional tools.

Conflicts of Interest: The authors declare no conflict of interest.

\section{References}

1. Rigillo, M.; Cervelli, E. Mapping Urban Vulnerability: The Case Study of Gran Santo Domingo, Dominican Republic. Adv. Eng. Forum 2014, 11, 142-148. [CrossRef]

2. Malekpour, S.; Brown, R.R.; de Haan, F.J. Strategic planning of urban infrastructure for environmental sustainability: Understanding the past to intervene for the future. Cities 2015, 46, 67-75. [CrossRef]

3. Sierra, L.A.; Yepes, V.; García-Segura, T.; Pellicer, E. Bayesian network method for decision-making about the social sustainability of infrastructure projects. J. Clean. Prod. 2018, 176, 521-534. [CrossRef]

4. Zhao, P.; Chapman, R.; Randal, E.; Howden-Chapman, P. Understanding resilient urban futures: A systemic modelling approach. Sustainability 2013, 5, 3202-3223. [CrossRef] 
5. Salas, J.; Yepes, V. Urban vulnerability assessment: Advances from the strategic planning outlook. J. Clean. Prod. 2018, 179, 544-558. [CrossRef]

6. Moraci, F.; Errigo, M.F.; Fazia, C.; Burgio, G.; Foresta, S. Making less vulnerable cities: Resilience as a new paradigm of smart planning. Sustainability 2018, 10, 755. [CrossRef]

7. Hurtado, S.D.G. Is EU urban policy transforming urban regeneration in Spain? Answers from an analysis of the Iniciativa Urbana (2007-2013). Cities 2017, 60, 402-414. [CrossRef]

8. Salas, J.; Yepes, V. MS-ReRO and D-ROSE methods: Assessing relational uncertainty and evaluating scenarios' risks and opportunities on multi-scale infrastructure systems. J. Clean. Prod. 2019, 216, 607-623. [CrossRef]

9. Dor, A.; Kissinger, M. A multi-year, multi-scale analysis of urban sustainability. Environ. Impact Assess. Rev. 2017, 62, 115-121. [CrossRef]

10. Rega, C.; Singer, J.P.; Geneletti, D. Investigating the substantive effectiveness of Strategic Environmental Assessment of urban planning: Evidence from Italy and Spain. Environ. Impact Assess. Rev. 2018, 73, 60-69. [CrossRef]

11. Salas, J.; Yepes, V. A discursive, many-objective approach for selecting more-evolved urban vulnerability assessment models. J. Clean. Prod. 2018, 176, 1231-1244. [CrossRef]

12. Penades-Pla, V.; Garcia-Segura, T.; Marti, J.V.; Yepes, V. A Review of Multi-Criteria Decision-Making Methods Applied to the Sustainable Bridge Design. Sustainability 2016, 8, 1295. [CrossRef]

13. Zio, E.; Bazzo, R. A clustering procedure for reducing the number of representative solutions in the Pareto Front of multiobjective optimization problems. Eur. J. Oper. Res. 2011, 210, 624-634. [CrossRef]

14. Ishibuchi, H.; Masuda, H.; Nojima, Y. Selecting a Small Number of Non-Dominated Solutions to be Presented to the Decision Maker. In Proceedings of the 2014 IEEE International Conference on Systems, Man and Cybernetics (SMC), San Diego, CA, USA, 5-8 October 2014.

15. Ishibuchi, H.; Akedo, N.; Nojima, Y. Behavior of Multiobjective Evolutionary Algorithms on Many-Objective Knapsack Problems. IEEE Trans. Evolut. Comput. 2015, 19, 264-283. [CrossRef]

16. Kukkonen, S.; Lampinen, J. Ranking-dominance and many-objective optimization. In Proceedings of the 2007 IEEE Congress on Evolutionary Computation, Singapore, 25-28 September 2007.

17. Kukkonen, S.; Deb, K. A fast and effective method for pruning of non-dominated solutions in many-objective problems. Lecture Notes in Computer Science (Including Subseries Lecture Notes in Artificial Intelligence and Lecture Notes in Bioinformatics). 2006. Available online: https://www.scopus.com/inward/record.uri?eid=2s2.0-33750253049\&partnerID=40\&md5=f46109796025a884fd054d73e71c308e (accessed on 9 November 2018).

18. Taboada, H.A.; Baheranwala, F.; Coit, D.W.; Wattanapongsakorn, N. Practical solutions for multi-objective optimization: An application to system reliability design problems. Reliab. Eng. Syst. Saf. 2007, 92, 314-322. [CrossRef]

19. Kasprzyk, J.R.; Nataraj, S.; Reed, P.M.; Lempert, R.J. Many objective robust decision making for complex environmental systems undergoing change. Environ. Model. Softw. 2013, 42, 55-71. [CrossRef]

20. Inselberg, A. Multidimensional detective. In Proceedings of the IEEE Symposium on Information Visualization, Phoenix, AZ, USA, 20-21 October 1997; pp. 100-107. Available online: https://www.scopus. com/inward/record.uri?eid=2-s2.0-0031332043\&partnerID=40\&md5=fab4a0dd73a75f7f1ac61fd6492cee9b (accessed on 9 November 2018).

21. Adger, W.N. Resilience, Vulnerability, and Adaptation: A Cross-Cutting Theme of the International Human Dimensions Programme on Global Environmental Change. Glob. Environ. Change 2006, 16, 268-281. [CrossRef]

22. Lempert, R.J. A new decision sciences for complex systems. 2002. Available online: http://people.physics. anu.edu.au/ \{\}tas110/Teaching/Lectures/L1/Material/Lempert02.pdf (accessed on 11 April 2019).

23. Thomas, J.; Kielman, J. Challenges for visual analytics. Inf. Vis. 2009, 8, 309-314. [CrossRef]

24. Andrienko, G.; Andrienko, N.; Demsar, U.; Dransch, D.; Dykes, J.; Fabrikant, S.I.; Tominski, C. Space, time and visual analytics. Int. J. Geogr. Inf. Sci. 2010, 24, 1577-1600. [CrossRef]

25. Santos, J.; Ferreira, A.; Flintsch, G. A multi-objective optimization-based pavement management decisionsupport system for enhancing pavement sustainability. J. Clean. Prod. 2017, 164, 1380-1393. [CrossRef]

26. Observatorio de Vulnerabilidad Urbana. Análisis urbanístico de barrios vulnerables. 2010. Available online: https://www.fomento.gob.es/MFOM/LANG_CASTELLANO/DIRECCIONES_GENERALES/ ARQ_VIVIENDA/SUELO_Y_POLITICAS/OBSERVATORIO/Analisis_urba_Barrios_Vulnerables/Informes_ CCAA.htm (accessed on 26 August 2015). 
27. Birkmann, J.; Garschagen, M.; Setiadi, N. New challenges for adaptive urban governance in highly dynamic environments: Revisiting planning systems and tools for adaptive and strategic planning. Urban Clim. 2014, 7, 115-133. [CrossRef]

28. Besagni, G.; Borgarello, M. The socio-demographic and geographical dimensions of fuel poverty in Italy. Energy Res. Soc. Sci. 2019, 49, 192-203. [CrossRef]

29. Khalil, N.; Kamaruzzaman, S.N.; Baharum, M.R. Ranking the indicators of building performance and the users' risk via Analytical Hierarchy Process (AHP): Case of Malaysia. Ecol. Indic. 2016, 71, 567-576. [CrossRef]

30. Pellicer, E.; Sierra, L.A.; Yepes, V. Appraisal of infrastructure sustainability by graduate students using an active-learning method. J. Clean. Prod. 2016, 113, 884-896. [CrossRef]

31. Sierra, L.A.; Yepes, V.; Pellicer, E. A review of multi-criteria assessment of the social sustainability of infrastructures. J. Clean. Prod. 2018, 187, 496-513. [CrossRef]

32. Saaty, T.L. How to make a decision-The analytic hierarchy process. Eur. J. Oper. Res. 1990, 48, 9-26. [CrossRef]

33. Singh, R.P.; Nachtnebel, H.P. Analytical hierarchy process (AHP) application for reinforcement of hydropower strategy in Nepal. Renew. Sustain. Energy Rev. 2016, 55, 43-58. [CrossRef]

(C) 2019 by the authors. Licensee MDPI, Basel, Switzerland. This article is an open access article distributed under the terms and conditions of the Creative Commons Attribution (CC BY) license (http://creativecommons.org/licenses/by/4.0/). 